\title{
Legal Analysis of Labor-management Conflicts in Labor-intensive Enterprises: An Empirical Study on Shandong Province
}

\author{
Bo Han \\ Civil and Commercial Law School \\ Shandong University of Political Science and Law \\ Jinan, China
}

\begin{abstract}
Purpose: The purpose of this paper is to study the causes of labor and capital conflict in labor-intensive enterprises, and then put forward the legal path to solve the labor-force conflict in labor-intensive enterprises. Design/methodology/approach-In this paper, taking Shandong Province as an example, this paper tries to analyze the conflict of labor-intensive enterprises in labor-oriented enterprises, and takes 2354 valid samples collected from the labor-intensive enterprises in Shandong province as the empirical research object. With SPSS19.0 Statistical analysis software, through the establishment of the nature of the enterprise, the industry belongs to the industry, the degree of education, etc. 108 variables, the use of empirical analysis, combined with literature search and interdisciplinary research and other research methods on Shandong Province laborintensive The harmonious degree of enterprise labor relations. Findings-Results revealed that older service employees experienced fewer customer stressors. Customer stressors mediated the negative relationship between age and burnout. Age was associated with use of passive avoidant (avoiding) and active constructive (problem solving) conflict management strategies. Furthermore, older employees used those strategies more effectively. Especially when avoiding conflicts, older employees reported more professional efficacy than younger colleagues. In contrast, younger employees benefited considerably less from strategy use and reported higher levels of burnout in general. Thus, results suggest older employees' effective conflict management and their positive perception of customer stressors contribute to lower levels of burnout. Practical implications-In order to alleviate the labor-force conflict in labor-intensive enterprises, we can improve the legal system of labor conflicts by establishing the correct solution to the conflict of labor and capital conflicts, strengthen the effectiveness of existing labor laws, implement the implementation system of labor conflicts, And other ways to resolve conflicts in a timely manner. In addition, we should give full play to the government, enterprises and the coordination of the role of workers, so that the protection of labor rights and interests. Through the benefit of consultation and balance, so that enterprises can be healthy development, workers feel the full "sense of access", this is to promote the harmonious and stable labor relations, to achieve the fundamental operation of social society. Originality/valueBased on the data, this paper analyzes the causes of the three types of labor conflicts and sums up the plight of labor and
\end{abstract}

capital conflict, puts forward the idea of establishing the correct conflict of labor and capital, and establishes the countermeasures of labor and capital consultation system in order to alleviate the conflict and construct labor- Type enterprise harmonious labor relations to provide an effective path.

Keywords-Labor-intensive enterprises; labor relations; labor conflicts

\section{INTRODUCTION}

Labor-intensive enterprises mainly depend on plenty of labor productivity in their production. China boasts its population resources. Besides, the threshold for establishment of such enterprises and their operating costs are relatively low. Since the reform and opening-up, a lot of labor-intensive enterprises have come into being as required in China. Different from general enterprises, China's laborintensive enterprises are characterized by large quantity, extensive distribution, uneven corporate management levels, low degree of professional technology and relatively low quality in whole, etc. As a result, varied LMCs exist in laborintensive enterprises such as low salary and welfare, long overtime, lack of corporate culture, high turnover and difficulty in recruitment. In recent years, LMCs represented by the Foxconn suicide incident happen in labor-intensive enterprises time and again. The quantity of labor disputes has increased with complicated forms, which reminds us that labor-management contradictions are an irrefutable fact (Zhou Xiaoguang, Wang Meiyan, 2015). Related studies show that the harmonious degree of the labor-management relation and national economic growth are in positive correlation. Favorable labor-management relations can effectively boost economic development. (Gong Jiyun, 2006) Hence, how to effectively mitigate labor-management contradictions and build harmonious labor-management relations is an important topic that is worth social attention and research. (Fang Fuqian, 2011) On this basis, this paper takes the example of Shandong Province and plans to conduct an empirical analysis of LMCs in labor intensive enterprises. 2,254 effective samples collected from the questionnaire survey on labor-intensive enterprises of Shandong Province are regarded as the research objects. 108 
variables including corporate nature, corporate industry and education background, etc. are set in SPSS19.0. Then it goes on to apply the empirical analysis approach and combine literature retrieval and inter-disciplinary research method, etc. to explore the harmonious degree of labor-management relations in labor-intensive enterprises of Shandong Province. It discovers and concludes main LMC types in laborintensive enterprises of Shandong Province, analyzes causes for appearance and development of conflicts, and tentatively proposes suggestions on easing LMCs in the hope of providing referable legal approaches for building harmonious labor-management relations.

\section{OVERVIEW OF LABOR-MANAGEMENT CONFLICT THEORIES}

\section{A. Connotations of Labor-management Conflicts}

Before learning about the connotations of LMCs, it's necessary to clarify the definition of labor-management relations which can be understood in a broad sense and in a narrow sense. In a narrow sense, labor-management relations refer to studies on working rules and systems in the workplace; in a broad sense, labor-management conflicts indicate behavioral and interactive relations between people at work. It studies how individuals, groups, organizations and institutions make decisions on standardizing labormanagement employment relations. (Wang Daqing, Jiao Jianguo, 2003). Regards to the definition of LMCs, the academic circle has different understanding based on issues being studied. Fajana A (Fajana A, 1986) maintained that LMCs were caused because employers and employees couldn't reach an agreement over common concerns. Fashoyin T (Fashoyin T, 1992) defined LMCs as temporary work suspension caused by dissatisfaction of specific employee groups. Quite a few scholars in China explained its connotations. According to CHANG Kai (Chang Kai, 2006), LMCs mainly referred to social behaviors of intensifying and publicizing labor disputes and contradictions. LI Min ( $\mathrm{Li}$ Min, 2002), et al. held that LMCs referred to the direct inconsistent interactive behavior process and confrontation between employees and employers because of a certain reason. WANG Weize believed that LMCs were psychological confrontation, disputes and frictions demonstrated due to labor-management differences in interest, purpose and expectation. This paper concludes that LMCs refer to psychological and behavioral statues shown because of disputes and reconciliation between employers and employees over interest, rights and obligations.

\section{B. Characteristics of Labor-management Conflicts}

Labor disputes are categorized based on contents of disputes. It can be divided into disputes over rights and disputes over interest according to whether employers and employees claim vested rights or new rights. (Dong Baohua, 2012). Disputes over rights occur based on legal and labor contracts. When enterprises breach the contract, corresponding disputes over rights will be produced; disputes over interest mean that employers and employees disagree over maintenance or alteration of current labor conditions.
It's usually triggered by changes in social development conditions or general economic situation. (Qian Weizeng, 2006). In terms of existing labor dispute cases, LMCs mainly center on disputes over rights. In other words, conflicts are generated for employees are dissatisfied with enterprises' failure to keep their word according to laws and regulations or labor contracts, mainly employers' delay in making payment, more overtime and adverse working environment, etc. However, with economic development and constant enhancement of laborers' awareness of safeguarding their own rights, the proportion of disputes over interest in LMCs has kept increasing. More and more laborers dare make their interest claims from their employers, require employers to provide higher salary and welfare and more comfortable working environment.

\section{Forms of Labor-management Conflicts}

There are many forms of LMCs which are reflected in protest, strike and malignant physical aggression, etc., which is deemed as an immense and complicated social phenomenon. (Olufemi, A. A, 2010) According to different subjects in the labor-management relations, it can be divided into conflicts respectively triggered by staff (employees) and enterprises (employers). In labor-intensive enterprises, labormanagement conflicts are basically demonstrated in the former, i.e. employees express their intolerance of unreasonable interest setting of enterprises by being slack at work, stopping working and creating high turnover. (Dauda, Y. A, 2006). In addition, LMCs can be presented as covert and overt conflicts. Covert conflicts refer to internal dissatisfaction which cannot be known by others. It's usually the prepositive process of overt conflicts. Overt conflicts include transgressing behavior and collective petition in the workplace, etc. (XI Meng, Zhao Shuming, 2014). Observing forms of labor disputes in labor-intensive enterprises in recent years, overt conflicts have been frequent, and become more intense in terms of degree of conflict and confrontation time.

\section{EMPIRICAL SURVEY ON THE STATUS QUO OF LABOR- MANAGEMENT CONFLICTS IN LABOR-INTENSIVE ENTERPRISES OF SHANDONG PROVINCE}

Shandong, as a large population province in East China, is at the critical period of economic transition and social transformation. Moreover, its population is huge and laborintensive enterprises are concentrated. Labor-management relations are more marketized, complicated and diversified, and become important issues that influence its economic and social coordinated development. It regards labor-intensive enterprises of Shandong Province as its research objects, collects research samples and further analyzes LMCs. It's typical and explanatory to some extent.

\section{A. Overview of Research Sample}

1) Basic information on the survey questionnaire: 3,410 questionnaires were handed out in this survey, including 310 enterprise-version questionnaires for the corporate management team and 3,100 staff-version questionnaires for 
corporate employees based on the ratio of 1:10. Survey respondents include labor-intensive enterprises of different nature such as state-owned enterprises, private enterprises and foreign-owned enterprises of Shandong Province. Meanwhile, it combines proportions of pillar industry and typical industry of Shandong Province to center on its characteristic industries such as nonferrous metal smelting, petrochemical engineering and textile. This paper tries to expand the survey scope and refine survey contents as much as possible within the research ability so that survey results can fully demonstrate Shandong's characteristics. At the same time, this questionnaire covers main aspects of labormanagement relations, including staff income, labor contract signing, labor dispute treatment, corporate culture construction, corporate staff life and working environment. It basically summarizes all factors influencing the construction of harmonious labor-management relations, and can reflect the status quo of labor-management relations of Shandong Province in a more objective way. 2,881 questionnaires in total are recovered, including 288 enterprise-version ones and 2,593 staff-version ones with a recovery rate of $84.4 \%$. With further selection, 2,254 effective questionnaires are obtained in the end, including 224 enterprise-version ones and 2,030 ones of staff version with an effective rate of $66.3 \%$. Hence, the questionnaire is sufficiently objective.

2) Basic information on respondents: In order to ensure randomness and scientific nature of the survey, this study gathers basic statistics of staff and their employers, mainly including six aspects of corporate nature, staff gender, staff age, staff working age and staff education background. Detailed statistical data is as follows:

a) Corporate nature:Over $60 \%$ of respondents come from private enterprises, being the largest group; the proportion of staff in foreign-owned enterprises is more than $20 \%$, being the second; staff of state-owned or collective enterprises only account for $10 \%$; the remaining staff are from other types of enterprises. In terms of involved industries, the ratio of petrochemical engineering is $24.1 \%$ which is the highest; then it's the textile and food processing industries respectively $18.2 \%$ and $14.5 \%$; the chemical pharmaceutical industry occupies $8.2 \%$; the material industry $7.7 \%$, light textile industry $5.4 \%$, the building industry $5.3 \%$ and other industries $16.6 \%$.

b) Staff gender: The proportions of female and male staff in the survey are balanced with the former being $52.7 \%$ and the latter $47.3 \%$.

c) Staff age: In terms of age, staff who age between 21 and 30 account for the highest ratio, about 50\%; those aging between 31 and 40 take up 30\%; the proportion of staff aging between 41 and 50 is $14.9 \%$; those aging below 20 and above 50 respectively account for $3.1 \%$ and $1.1 \%$ which are relatively low ratios.

d) Staff working age: Staff in the survey whose working age is less than 5 take up a larger proportion, being close to $60 \%$. The ratio of those with a working age between 5 to 10 is $30 \%$; less than $10 \%$ for those with a working age between 10 to 15 . There are very few staff whose working age is greater than 15. The working age is small on the whole in labor-intensive enterprises, which shows the feature of high turnover.

e) Staff education background: Staff whose education background is junior high school and below account for $15.3 \%$; $31 \%$ for those with a background of senior high, technical school or vocational school; $31.8 \%$ for those with a junior college degree; $21 \%$ for those with a bachelor's degree and only $0.9 \%$ for staff with a master's degree or above. Therefore, the education background of staff in labor-intensive enterprises of Shandong Province is mostly junior college and below, which takes on a generally low education degree trend.

\section{B. Data Results Display}

Through statistical analysis of the survey data, the author found that in labor-intensive enterprises of Shandong Province, LMCs mainly focus on three aspects including salary, welfare and corporate management system. Details are as follows:

1) Salary: According to data announced by Shandong Provincial Bureau of Statistics on June 3, 2016, five insurance payment policies based on per capita income of RMB 4,772/month were released in July 2016. The proportion of employees in labor-intensive enterprises of Shandong Province whose salary is below RMB $4,251 /$ month is up to $82 \%$. In other words, the monthly income of more than $80 \%$ of staff is below the per capita income level of the province. At the same time, the proportion of corporate staff who believe there's no difference between real salary and ideal salary is $5.1 \%$ only. The majority of them maintain that their monthly income should be increased on the current basis. More than $30 \%$ of the believe that the range should be between RMB 500 and 1,00 while about $30 \%$ of them claim a range between RMB 1,000 and 2,000. In labor-intensive enterprises, three main problems exist in terms of salary, including slow raise, low salary level and few bonuses and subsidiaries. As shown by the data, over $30 \%$ corporate staff hold that the raise growth is too slow and about $30 \%$ of them think the salary level is on the low side while more than $20 \%$ maintain that more bonuses and subsidiaries should be provided for corporate staff. Likewise, in the survey on enterprises, about $30 \%$ enterprises remark that the greatest problem of labormanagement relations is that staff has excessively high expectation of their salary and there's difficulty in raising their salary. About 50\% enterprises refer to their operation conditions and staff salary level while formulating salary standards. About $30 \%$ enterprises mainly draw upon the salary growth instruction line of local places. It can be noted that the norm for salary standards is dull in labor-intensive enterprises of Shandong Province and staff individuals' 
demands are overlooked. It can be concluded from the data analysis above that the enterprises and staff have major disagreement over salary which is the most important LMC in labor-management relations. Conflicts are demonstrated in the following two aspects:

- The overall salary level of staff in labor-intensive enterprises of Shandong Province is low on the whole, and the growth is slow. Besides, staff has higher expectations about their salary income.

- The reference norm for salary standards is dull when labor-intensive enterprises of Shandong Province formulate them. The salary system is unsound and staff demands are ignored. In the meantime, due to characteristics of labor-intensive enterprises, these enterprises' ability to increase staff salary is limited.

2) Welfare: The contradiction over the welfare of staff is the second largest LMC following the salary. About $20 \%$ staff are dissatisfied with welfare provided by enterprises which equally believe that welfare is one of important reasons for tense labor-management relations. Meanwhile, in labor-intensive enterprises of Shandong Province, what staff expect most are paid leave, transportation allowance and regular physical check-up or health subsidy, which respectively account for $21.1 \%, 20.2 \%$ and $19.7 \%$. In the view of enterprises, among all welfare, it's the most difficult thing to provide regular traveling, paid leave and regular physical check-up or health subsidy. Hence, the conflicts between enterprises and staff in terms of welfare in laborintensive enterprises of Shandong Province are mainly demonstrated in the following aspects:

- The welfare level in labor-intensive enterprises of Shandong Province is on the low inside and enterprises bear great burden for welfare growth.

- Staff hopes that enterprises can provide various forms of welfare, especially non-cash welfare.

- The contradiction over paid leave and regular physical check-up or health subsidy is the most prominent between employers and employees.

3) Corporate management system: Corporate management system is the communication medium between enterprises and their staff. According to the survey data, among labor-intensive enterprises of Shandong Province, the management systems of quite a few enterprises are unreasonable. Over $30 \%$ of corporate staff state that the corporate management is strict and about $10 \%$ of them are of the opinion that the management system is overly strict and the management team is rude. Even worse, in some enterprises, staff is abused and maltreated. At the same time, more than half of these enterprises fall short of explicit punishment and reward systems. The methods of punishment and reward are mostly determined by the management team or the reward is less while punishment is unreasonably high, etc. Meanwhile, while managing its staff, enterprises face varied problems. More than half of these enterprises maintain that high turnover brings about great difficulty for their management while about $20 \%$ of them conclude that staff and enterprises are lack of communication and exchange, and $10 \%$ of them realize that corporate management is disturbed due to inconsistence with staff in terms of welfare. The statistical data on enterprises suggests that enterprises and staff have obvious conflicts particularly in corporate management system. As shown by results of the survey on staff's favorite corporate culture and psychological counseling provided by enterprises for their staff, more than $30 \%$ of staff like enterprises which can provide more staff training and value individual development. About $30 \%$ of them prefer enterprises which can organize entertainment and cultural activities with harmonious atmosphere. More than $70 \%$ of these enterprises fail to offer timely psychological counseling for their staff. Staff hopes that enterprises can organize activities and conduct psychological training in terms of psychological counseling so as to alleviate their work pressure. Whether a corporate management system is sound and reasonable or not becomes one of most important factors influencing whether labor-management relations are in harmony or not. Through relevant data analysis, indeed, corporate management systems of labor-intensive enterprises of Shandong Province have certain problems and LMCs are mainly demonstrated in the following aspects:

- Unsound and implicit punishment and reward systems of enterprises lead to dissatisfaction of their staff.

- Excessively high turnover generates barriers for corporate management of labor-intensive enterprises of Shandong Province, thus being unable to form a fixed and uniform management mode.

- Staff favors enterprises which pay attention to individual development and build a harmonious atmosphere, which is completely not in line with the current operation and management mode of laborintensive enterprises. The conflict between staff's pursuit of individualization and enterprises' monotonous labor mode with low technicality is obvious.

- The majority of labor-intensive enterprises are in badly needs of timely psychological counseling for their staff because they pay less attention to the psychological health of their staff. Staff's psychological pressure at work cannot be relieved, thus increasing the occurrence possibility of extreme incidents.

\section{CAUSES FOR LABOR-MANAGEMENT CONFLICTS}

According to Marx, in labor-management relations, labor force is a commodity and salary is the price of the labor force (Marx, 1975), which determines the weak position of laborers. Compared with the powerful capital, the position of laborers has kept declining. At present, Shandong is at a 
critical period of old and new kinetic energy transformation. Profound reform is taking place in both economic operation and resource allocation. The great influx of workers injects great vitality into the development of local labor-intensive enterprises. Meanwhile, labor-management relations between enterprises and staff are more complicated and severe, and have turned into an important issue that influences economic and social coordinated development of Shandong Province.

Pursuant to further analysis of the survey data, the author holds that labor-management contradictions between laborintensive enterprises of Shandong Province and their employees mainly center on salary, welfare and corporate management system. Concrete reasons are presented below.

\section{A. Salary}

In labor-intensive enterprises of Shandong Province, the conflict in salary mainly lies in low income level of staff and slow salary growth; staff expects higher income while enterprises have limited ability to increase the salary income of their staff. At the same time, enterprises refer to single norms for salary standard formulation and their internal salary system is not improved with staff demands being ignored. Reasons are as follows:

- Labor-intensive enterprises have their own characteristics. Compared with technology-intensive and capital-intensive enterprises, labor-intensive enterprises principally depend on plenty of cheap labor forces for production and operation and are characterized by low technological cost and low equipment cost. Enterprises in the author's survey are petrochemical, textile and food processing industries, etc. in which slow growth and fixed profit space are universal. Moreover, these traditional industries don't pay attention to upgrading of production technology. As a result, their long-term backward technology and equipment are used to maintain corporate operation, which leads to narrower space for further development. (LANG Xianping, 2014). Hence, the strength of labor-intensive enterprises is to utilize the low-cost labor forces to produce. Corporate pursuit of maximized profit and staff pursuit of maximum income come into conflicts, which mean that it's impossible for enterprises to provide high income for their staff. At the same time, limited corporate development is the most important reasons for general low income of staff and slow income growth.

- Most of labor-intensive enterprises fall short of regular and effective salary systems. On July 9, 2009, All-China Federation of Trade Unions issued "Instructive Opinions About Proactively Conducting Collective Negotiation of Industrial Salary" which clearly stated that when China's non-public small and medium-sized enterprises formulated salary standards for employees, corporate representatives should negotiate and discuss with industrial trade unions or local trade unions rather than making decisions alone. However, according to the author's survey, the proportion of enterprises in surveyed labor-intensive enterprises of Shandong Province which determine salary systems by virtue of democratic means of workers' congress and negotiation is less than $50 \%$, which means that the majority of these enterprises didn't obtain consent and approval of their employees while setting up salary standards. The salary income is the most important living source for staff's basic necessities of life. Should enterprises fail to listen to their employees while making the important standards and staff's right to participate in corporate management is not fulfilled, it's not strange that labor-management relations become tense.

- The government support for labor-intensive enterprises is weak. On December 31, 2013, the Ministry of Industry and Information Technology together with eight other departments such as the NDRC and Ministry of Finance announced "Instructive Opinions about Promoting Healthy Development of Labor-Intensive SMEs" to mitigate sudden issues of labor-intensive SMEs and boost healthy development enterprises. Therefore, eight detailed measures were put forward, such as guiding folk investment to labor-intensive enterprises, substantially reducing enterprises' tax burden, making greater efforts to provide fiscal policy support and solving financing difficulty. Shandong Provincial People's Government released "Implementing Opinions About Further Supporting Healthy Development of Micro and Small Enterprises" ("Opinions" for short) on July 12, 2012. The "Opinions" stipulated relevant regulations for support for micro and small enterprises but didn't clearly point out detailed measures for labor-intensive enterprises. Insufficient government support makes labor-intensive enterprises face great pressure in such aspects as expansion of production scale, improvement of production technology and acquisition of loans. If corporate benefits are not enhanced, it's inevitable that staff's high-level salary income cannot be materialized.

- Staff's living demands cannot be satisfied because of the increase in living costs caused by increasing prices of commodities

- In recent years, China's price has risen rapidly but the income growth of staff in labor-intensive enterprises is far behind the price growth range. Excessively high living costs bring about great pressure for corporate staff. In labor-intensive enterprises, staff makes a living purely through their labor forces, which is more apparent compared with staff in other types of enterprises. Consequently, corporate staff is more sensitive to income level and growth, and have higher demand for increase in their income. The problem of salary income has accordingly become the most important crux for LMCs. 


\section{B. Welfare}

Welfare is one of important reasons for deepening LMCs. Labor-intensive enterprises of Shandong Province provide a generally low level of welfare for their staff. In face of staff's higher expectations for non-cash welfare, enterprises express great pressure. Enterprises and staff have the greatest conflicts in two aspects: paid leave and regular physical check-up or health subsidy. Main reasons are as follows:

- Welfare is an important index that is used to measure the income level of corporate staff. According to related data, the ratio between individual salary and welfare in the world's top 500 enterprises is almost $1: 1$. What's covered in welfare such as transportation fee, lunch, paid leave and professional training directly matter for staff's immediate interest. Hence, in addition to salary, welfare is a significant standard for measuring individual income of staff. In the meantime, staff will have a stronger sense of belonging with enterprises which provide satisfying welfare. With gradual improvement of people's living standards, corporate staff has greater demands for non-cash welfare such as paid leave and organization of travels, which reflects a transition in modern corporate staff's opinions. It's the reason as well why the quantity of LMCs in terms of welfare has dramatically gone up.

- The working nature and working environment of labor-intensive enterprises of Shandong Province are special. Among these enterprises in the author's survey, the majority belong to the heavy industry which is determined by the industrial structure of Shandong Province. About $70 \%$ of corporate staff maintain that the working environment contains physical pollution that endangers human health such as dust, poisonous gas, intense noise and excessively high temperature or faces problems of flammable and combustible material storage and severe health conditions. Hence, it can be noted from the survey data that staff greatly calls for regular physical checkup or health subsidy. Yet, the majority of enterprises signify that out of consideration for operating costs, they are unwilling to provide such welfare with unobvious profit effect for their staff. The interest gaming between employers and employees makes potential conflicts of welfare prominent.

- Out of consideration for production and operation, labor-intensive enterprises cannot provide too much non-cash welfare for their staff. The development characteristics of these enterprises don't allow them to provide high salary income for their staff and besides, they cannot meet staff's demands for greater non-cash welfare, which has been analyzed in detail in the previous part. Besides, staff's paid leave and traveling requirements are concentrated in time, which will lead to dramatic fall in the corporate productivity at a certain time, thus severely affecting normal production and operation of enterprises and bringing about immense pressure for enterprises. As a result, labor-intensive enterprises are usually unwilling to provide too much non-cash welfare for their staff.

\section{Corporate Management System}

As shown by the survey results, it's common among labor-intensive enterprises that labor-intensive enterprises have such shortcomings as lack of improved punishment and reward systems, implicit punishment and reward regulations and unsound psychological counseling measures which may cause staff dissatisfaction. On the contrary, high turnover makes it difficult to build a fixed and uniform management mode and higher requirements for staff skills spell greater obstacles for management of labor-intensive enterprises of Shandong Province. In addition, the new generation of young workers' strong pursuit of freedom and personality breaks away from the backward operation and management mode of enterprises. Unsound corporate management systems bring about immense challenges to the construction of harmonious and stable labor-management relations. Main reasons are as follows:

- Governments don't have instructive standards for enterprises' punishment and reward systems which are random. The State Council announced Regulations on Punishment and Reward for Corporate Staff on April 10, 1982. Later on, it's replaced by the Labor Law of the People's Republic of China promulgated on July 5, 1994 and the Labor Contract Law of the People's Republic of China released on June 29, 2007. Since then, China hasn't established any law and regulation special for corporate punishment and reward system for staff. Shandong Province didn't formulate any relevant policy either. As a result, given lack of uniform standards, different enterprises vary in their punishment and reward solutions and measures, and sometimes, great differences exist. Enterprises consider more about their operation and revenue and less about staff's personal feelings when setting up such systems. Therefore, their punishment and reward system cannot be fully recognized by their staff. Besides, these systems mostly focus on punishment in the form of salary deduction, which is directly related with staff's individual income, thus being likely to cause LMCs between enterprises and staff.

- It's highly costly and difficulty to upgrade for enterprises. First of all, the production environment of labor-intensive enterprises is mostly large workshops which are different from the standardized office model in modern enterprises. For such traditional enterprises, it's costly and moreover not practical to conduct modern transformation or upgrading. Second, the management model of traditional labor-intensive enterprises is fixed and most of them don't have mature corporate culture so they do not value corporate development strategies that aim for longterm development as modern enterprises do. (LIU Taihong, TANG Ming, 2008) For instance, psychological counseling entails human costs such as 
recruitment of professional psychological counselors, organization of psychological counseling activities and print-out of related materials, which cannot create obvious value for enterprises within a short time. Most of labor-intensive enterprises believe it's not necessary to invest in such activities which don't "give back". Third, Shandong Province is a province with a huge population with a great density and high turnover of external population. As a result, enterprises face problems of poor stability of staff, frequent job-hopping and thus uncertain management objects, let alone a fixed management model. All these are barriers for these enterprises if they intend to shift their management systems.

- The new generation of corporate staff is different from the older generation in that the new generation is young, mostly born in 1980s and 1990s. Unlike the older generation, they have wide channels of gaining information in a timelier way. Besides, they have abandoned the obsolete concept of "staying in one enterprise in their entire lifetime". Therefore, the turnover is greater. Influenced by modern corporate culture, young corporate staff regards working comfortability as an important measurement standard. At the same time, the new generation has distinct personalities and a greater proportion of staff with education background. They are no longer satisfied with mechanical labor at the production line; instead, they love creative work more, emphasize realization of self-value and desire self-display. All staff hope that they are irreplaceable in the workplace. Newtype laborers yearn for honing and improving of individual abilities while working instead of surviving only. Moreover, their legal awareness and awareness of safeguarding their own and interest have been heightened. With popularization of legal knowledge and humanistic ideology and weakened credibility between people, corporate staff has gradually raised their own consciousness about rules. Staff hopes to see clear-cut systems and rules of enterprises and expect to be treated in a fairer way. If enterprises fall short of clear systems and rules, staff will be unable to accurately learn about the management goals of enterprises, which will bring about inconvenience for staff's work. Consequently, the new generation of staff is unsatisfied with the old corporate management model, which further leads to LMCs.

\section{COPING STRATEGIES FOR LABOR-MANAGEMENT CONFLICTS}

It's shown by data analysis that LMCs mainly concentrate on salary, welfare and corporate management system in labor-intensive enterprises of Shandong Province. Meanwhile, tense labor-management relations caused by conflicts are mainly demonstrated in low salary level and slow growth, less welfare provided and inhuman corporate management system. The occurrence of labor-management conflictions and even conflicts indicate that still a lot of shortcomings exist in the construction of LMCs treatment mechanism in China which requires further improvement by means of making up for legal loopholes and building a reasonable conflict solution mechanism, etc. Addressing LMCs and alleviating the tense bilateral relations are of important significance to promoting the benign operation of labor relations in Shandong Province and further constructing harmonious labor-management relations in Shandong Province. Timely treatment of LMCs can be conducted through multiple approaches, such as establishing correct philosophies of solving LMCs, improving legal systems for solving LMCs, strengthening the efficacy of current labor laws, implementing the mechanism of solving LMCs and setting up a labor-management negotiation mechanism. Besides, while acting out those approaches, coping with LMCs entails cooperation of governments, enterprises and corporate staff, and improvement and transformation in multiple aspects such as policy, system, ways of management and philosophy, etc. Hence, the author attempts to propose the following coping strategies.

\section{A. Establishing Correct Philosophies of Solving LMCs}

LMCs are inevitable products of market economy. Labor and capital force is an inherent paradox, which is an unavoidable topic in the economic development process. To effectively solve increasing LMCs in labor-intensive enterprises, the first thing to do is to have a new understanding in terms of concept:

1) Solving LMCs can't deviate from Marx's labor relation theory: The essence of LMCs must be understood in order to solve them. According to Marx, capital and labor are the most basic relation in market economy and the main contradiction that influences development. Hence, as the product of capital and labor, LMC is a normal economic phenomenon and in line with Marx's labor relation theory. (Marx, 1972). Therefore, while solving LMCs, they cannot be "overly packaged" and interpreted as interest demand of political tint because it obviously breaks away from Marx's labor relation theory and will further intensify contradictions, thus being harmful to conflict removal. Accordingly, Marx's labor relation theory should be abided by to comprehend the essence of LMCs and further locate the source. It's an ideology that should be strengthened in the process of managing LMCs.

2) The concept and awareness of regarding labor and capital as the subjects in the process of solving LMCs: When enterprises and laborers face labor disputes, they usually resort to government departments and deem it as the responsibility of the government sector. They hope that governments can take charge. Labor and capital are involved parties in the LMCs whose communication and exchange are the most direct way of resolving contradictions and mitigating labor-management relations. However, they usually ignore the means of negotiation and excessively depend on government departments. Hence, they should establish the concept and awareness of regarding themselves as the subjects in the process, consider 
their bilateral information communication as the primary task and proactively seek means of self-help.

\section{B. Improving Legal Systems for Solving LMCs}

To solve LMCs in labor-intensive enterprises, there must be a legal basis. The following aspects can be emphasized to address numerous relevant problems such as ambiguous labor laws, systems and regulations, weak operability, unequal bilateral responsibilities and existence of legal loopholes:

1) Judicial interpretation can be used to clarify connotations of legal terms and make laws more operable: A number of legal terms in the labor law are vague and some of them are not operable, which makes legal applicability difficult. First, the scope of legal application is implicit; second, even if the scope of applicability is clear, different ways of understanding laws lead to inconsistence in legal application. In order to cope with this problem, the author suggests that judicial interpretation should be applied to clarify connotations of legal terms and make laws more operable. For instance, in terms of raise, the form of judicial interpretation can be adopted to elaborate the reference basis, range and minimum period for increase in salary, which will provide favorable instructions for enterprises to make decisions about raise. Moreover, it can reduce the possibility of different verdicts by different judges to some extent, and thus establish judicial authority. (Zhao Gang, 2010)

2) Labor policies should be adjusted to change the situation of unequal legal responsibilities between two parties: The division of rights and obligations for labor and management parties in the labor law is unfair to some extent. For enterprises, they have an obvious advantage of economic strength and grasp more information. Under such circumstance, the cost of breach of contract for enterprises is quite low. It's ubiquitous that labor-intensive enterprises illegally terminate their contracts with laborers. The contents of laws cannot be altered but government departments can favor weak laborers while formulating labor policies. For example, if enterprises don't act in accordance with laws, government departments can provide relevant reliefs for the unemployed, and meanwhile cancel the reward of the next year for those enterprises which illegal terminate labor contracts for many times, etc. Such similar labor policies can be introduced to turn the situation of unequal legal responsibilities between labor and management parties.

3) Loopholes in the labor law should be compensated according to actual conditions of social and economic development: Laws inevitably lag behind and the existing laws are insufficient to cope with the changeable reality. Although on the basis of the Labor Law several labor laws such as the Labor Contract Law, Employment Promotion Law and Social Insurance Law have been successively announced since 2007, special laws for the adjustment of labor-management relations are not formulated yet. Hence, it's especially important to fill in the blank of labor laws and make up for legal loopholes in accordance with practical needs of economic development.

\section{Strengthening the Efficacy of Current Labor Laws}

The efficacy of Chinese labor laws represented by the Labor Contract Law is on the low side. It's extremely common that enterprises don't follow laws and regulations to sign labor contracts and perform labor contracts. The efficacy of labor laws should be consolidated by increasing the costs for violating labor laws and establishing a labormanagement balance mechanism:

1) The costs for violating labor laws should be increased: The main reason for low legal efficacy is low costs for violation. The cost for law violation cannot damage the fundamental interest of lawbreakers. Hence, to enhance the efficacy of current labor laws, the cost for violation must be greatly raised. Violating enterprises and laborers should be punished and registered in credit archives by establishing an explicit punishment mechanism and a credit archives system. Besides, it will be disclosed to the public as an important reference for corporate recruitment and laborers' selection of employers. Once enterprises or laborers go against the labor laws, their operation or reemployment will be affected adversely. In this way, violating enterprises and laborers will be punished. Moreover, it will deter potential lawbreakers in a legal sense. It can not only increase the cost for law violation but also reinforce the implementation efficacy of laws.

2) A labor-management balance mechanism should be set up: Establishing a labor-management balance mechanism and using the force of laborers to restrain and balance the strength of the management party can help prompt enterprises to observe labor laws and regulations, thus strengthening legal efficacy. The establishment of a labor-management balance mechanism should focus on how to strengthen the balance force of laborers, which can be realized by accelerating the reform of trade union and improving laborers' position in the negotiation process. (WANG Xinrong, 2014) When the connection between the trade union and corporate staff is reinforced and the position of the trade union is gradually elevated, it will bring about pressure to the management parties and restrain and standardize employers' recruitment conduct to some extent, thus greatly benefiting the enhancement of labor law efficacy.

\section{CONCLUSION}

On February 27, 2015, the general secretary XI Jinping proposed to make people have a "sense of gain" at the tenth session of the central comprehensively deepening reform team. Plenty of LMCs exist in labor-intensive enterprises fundamentally because of insufficient "sense of gain" for corporate staff. Since the reform and opening-up, the economic and social structure reform under the socialist market economy system has brought about profound changes 
in labor-management relations. (LIU Jianxi, HAO Liaogang, 2014) Labor-management relations are one of the most important social relations, covering economic, social and national stability aspects. At present, China is at the rapid development stage of economic transformation. Facing the pattern of "emphasis on capital and ignorance of labor" under the background of economic marketization, LMCs have become more and more intense, and are extremely likely to trigger mass disturbance, which is especially obvious in varied labor-intensive enterprises. (RONG Zhaozi, 2010) In face of superb economic data, we should pay more attention to how to safeguard the legal rights and interest of corporate staff who are on the weak side, and meanwhile take note of the development dilemma facing labor-intensive enterprises. Hence, regards to LMCs in labor-intensive enterprises, multiple approaches can be adopted to timely solve them, such as establishing correct philosophies of solving LMCs, improving legal systems for solving LMCs, strengthening the efficacy of current labor laws, implementing the mechanism of solving LMCs and setting up a labor-management negotiation mechanism. In addition, the coordinative role of the governments, enterprises and staff should be played to guarantee labor-management rights and interest. (TAN Hong, 2014) To truly make enterprises achieve healthy development and staff have a strong "sense of gain" through interest negotiation and balance is the fundamental means of facilitating harmonious and stable labor-management relations, and realizing favorable social operation.
Nigerian Journal of Labor Law and Industrial Relations, 2006, 1 (1), P 26-44.

[12] Xi Meng, Zhao Shuming. A Literature Review of Industrial Relations Conflicts: Definition, Antecedents and New Research Perspective. Chinese Journal of Management, Volume 79, 2014 (3). (in Chinese)

[13] Marx. Capital. Volume 1. Beijing: People's Publishing House, 1975. (in Chinese)

[14] Lang Xianping. On How Reforms Set Out Again. Beijing: Oriental Publishing House, 2014. (in Chinese)

[15] Zhao Gang. Judicial Confirmation: Simplification of Complicated Labor Disputes. People's Court Daily, April 19, 2010, P 1,3-6. (in Chinese)

[16] Wang Xinrong. Expansion and Perfection of Trade Union Functions in the Era of "Rights" from a Perspective of State Governance Modernization. Socialism Studies, Volume 88, 2014 (6). (in Chinese)

[17] Liu Jianxi, Hao Liaogang. An Empirical Study on China's LaborManagement Relations Coordination Mechanism in the Transition Period. Soft Science, Volume 66, 2014 (4). (in Chinese)

[18] Rong Zhaozi. The Way to Harmony: A Study on Contemporary China's Labor-Management Relations. Beijing: China Renmin University Press, 2010. (in Chinese)

[19] Tan Hong. Exploration of Problems, Dilemma and Characteristics of China's Labor-Management Relations in the Transition Period. Shandong Social Sciences, Volume 97, 2014 (7).

\section{REFERENCES}

[1] Zhou Xiaoguang, Wang Meiyan. The Status Quo, Characteristics and Resolutions of Labor-Management Conflicts in China. Academic Research, Volume 33, 2015 (4), P38-41. (in Chinese)

[2] Gong Jiyun (2006). A Study on China's Labor Relations in the Transition Period. Hefei, Anhui: Anhui People's Publishing House, 2006. (in Chinese)

[3] Fang Fuqian. Conflict and Harmony: The Reality and Evolution of Contemporary China's Labor-Management Relations. China Review of Political Economy, Volume 86, 2011 (3), P38-41. (in Chinese)

[4] Fajana, A.. Industry Harmony in Developing Countries [J]. Business and Financial Analyst, 1986, 3 (6), P38-41.

[5] Fashyin, T., Avoidance of Conflict for Corporate Advancement [J]. Nigeria Journal of Industrial Relation, 1992, 2 (8), P20-36.

[6] Chang Kai. Legal Treatment of Labor-Management Conflicts: An Imperative Political Task of Building Harmonious Labor Relations. Chinese Cadres Tribune, Volume 83, 2006 (12). (in Chinese)

[7] Li Min, Zhang Tong. A Review of the Research in the Management of Labor Disputes in Western Countries. Journal of South China University of Technology (Social Science Edition), Volume 55, 2002 (4). (in Chinese)

[8] Dong Baohua. On Mechanism and Legitimacy Limit of Laborers' Spontaneous Strike. Gansu Social Sciences, Volume 90, 2012 (1). (in Chinese)

[9] Qian Weizeng. The Survey Report of the International Labor Organization Shows Severe Employment Situation for Global Youth. Workers' Daily, November 1, 2006, P1, 3-4. (in Chinese)

[10] Olufemi, A. A., Collective Bargaining as a Strategy for Industrial Conflict Management in Nigeria [J]. Journal of Research in National Development, 2010, 8 (1), P 215-232.

[11] Dauda, Y. A. Employment of Independent Arbitrators in the Management of Trade Disputes and Industrial Crisis in Nigeria [J]. 